\title{
Relationship between Flag Leaf Characteristics and Main Yield Components in Oat (Avena sativa L.)
}

Ionuț RACZ ${ }^{1}$, Rozalia KADAR ${ }^{1}$, Sorin VÂTCĂ², Ioana Virginia BERINDEAN², Adrian CECLAN ${ }^{1}$, Diana HIRIȘCĂU ${ }^{1,2}$, Camelia URD $\breve{A}^{1}$

${ }^{1}$ Agricultural Research and Development Station Turda

${ }^{2}$ University of Agricultural Science and Veterinary Medicine Cluj Napoca

*corresponding author: racz_ionut@yahoo.com

Bulletin UASVM series Agriculture 76(1) / 2019

Print ISSN 1843-5246; Electronic ISSN 1843-5386

DOI:10.15835/buasvmcn-agr: 2018.0047

\begin{abstract}
The objective of this study was to investigate relationships between leaf area index, leaf chlorophyll concentration, yield components and grain yield in oat (Avena sativa L.). Ten oat varieties were analyzed in field conditions regarding those traits. Flag leaf chlorophyll concentration range between 451.51 and 747.79 units of $\mu \mathrm{mol}$ of chlorophyll per $\mathrm{m}^{2}$. Also, leaf area index range between 13.68 to $32.84 \mathrm{~cm}^{2}$. Significant correlation indices were highlighted between yield components and leaf area index, yield/yield components and chlorophyll concentration of flag leaf.
\end{abstract}

Keywords: Avena sativa, flag leaf, yield components

\section{Introduction}

Common oat (Avena sativa L.) is one of the major crops in temperate climate zones used both for human and animal nutrition (Sadiq Butt et. al. 2008). In cereals, grain yield is mainly dependent on photosynthetic source-sink relationship dictating changes in carbohydrate synthesis, accumulation and partitioning (Berwal et al., 2017). Flag leaves and chlorophyll pigments occupies a unique role in the physiology, productivity and economy of green plants. Leaf area index (LAI) is an important structural property of vegetation, because leaf surfaces are the primary border of energy and mass exchange.

\section{Materials and methods}

The field experiments with oats were conducted in Agricultural Research and Development Station from Turda under normal crop conditions. The Apogee MC 100 was used to measure the amount of chlorophyll concentration ( $\mathrm{Chl} \mathrm{C}$ ) in the flag leaf, by transmitting light from light emitting diodes (LED) through a leaf at wavelengths of 650 and $940 \mathrm{~nm}$ to estimate chlorophyll concentrations (units of $\mu \mathrm{mol}$ of chlorophyll per $\mathrm{m}^{2}$ ) at GS 83 stage at the same time were determinate leaf area index (LAI) for cereal crop according to Quarrie and Jones equation where: Leaf area index = Length x Breadth x 0.75 (Aldesuquy et al., 2014). Grain yield (GY) and its main components were estimated at harvest. In the analysis of the panicle components, there was a random collection of 10 oat panicles per experimental unit. The followings were measured: number spikelet per panicle (NSP, n), number of grains per panicle (NGP, n) and grain mass of panicle (GMP, g). The obtained results were statistically processed by MS Excel program package using the methods of descriptive statistics; arithmetic mean value and standard deviation were calculated for each measured and calculated parameter.

\section{Results and Discussions}

As a reflection of plant photosynthetic capacity, chlorophyll concentration values have ranged between 451.51 at $V 2$ to 747.79 units of $\mu \mathrm{mol}$ of 
Table 1. The variability of studied traits of ten oat varieties

\begin{tabular}{ccccccccccccc}
\hline & V 1 & V2 & V 3 & V 4 & V 5 & V 6 & V 7 & V 8 & V 9 & V 10 & & CV \% \\
\hline NSP & 41.4 & 37.1 & 31.2 & $\underline{61.2}$ & 48.9 & 27.8 & 54.1 & 35.6 & 42.5 & 42.5 & 42.2 & 24.3 \\
\hline NGP & 78.2 & 55.6 & 53.8 & $\underline{110.6}$ & 90.2 & 46.1 & 97.6 & 72 & 77.5 & 68.2 & 75.0 & 27.2 \\
\hline GMP & 2.35 & 1.73 & 1.49 & $\underline{3.14}$ & 2.33 & 1.38 & 2.72 & 2.05 & 2.46 & 1.97 & 2.16 & 25.41 \\
\hline Chl C & 514 & 452 & 459 & $\underline{\mathbf{7 4 8}}$ & 575 & 457 & 571 & 562 & 694 & 573 & 560 & 17.7 \\
\hline LAI & 20.7 & 15.3 & 17.0 & $\underline{32.8}$ & 17.6 & 13.7 & 23.5 & 21.5 & 19.8 & 18.4 & 20.0 & 26.8 \\
\hline GY & 4.7 & 3.45 & 2.98 & $\underline{6.27}$ & 4.66 & 2.76 & 5.43 & 4.11 & 4.92 & 3.95 & 4.32 & 25.41 \\
\hline
\end{tabular}

Table 2. Correlation coefficient between main yield components and flag leaves

\begin{tabular}{cccccc}
\hline & NGP & GMP & Chl C & LAI & GY \\
\hline NSP & 0.96 & 0.94 & 0.77 & 0.82 & 0.94 \\
\hline NGP & - & 0.97 & 0.80 & 0.86 & 0.97 \\
\hline GMP & & - & 0.85 & 0.88 & 0.99 \\
\hline Chl C & & & - & 0.79 & 0.85 \\
\hline LAI & & & & - & 0.88 \\
\hline P $5 \%=0.63$ P $1 \%=0.76$ & & & & &
\end{tabular}

chlorophyll per $\mathrm{m}^{2}$ at $\mathrm{V} 4$ (Tab. 1); with an average value of 560.35 units of $\mu \mathrm{mol}$ of chlorophyll per $\mathrm{m}^{2}$. Also, leaf area index of the flag leaf of studied oat varieties have ranged between 13.68 to 32.84 with a mean of $20.02 \mathrm{~cm}^{2} / \mathrm{m}^{2}$. Regarding main yield components (number of spikelet's/panicle; number of grains/panicle; weight of grains/ panicle and grain yield) these have a specific reaction as a results of their capacity to adapt to different climatic conditions.

Based on the coefficient of correlation between flag leaf characteristics and yield components (Tab. 2), the agronomic performance of oat variety can be appreciated together with chlorophyll concentration or leaf area index. The strong and positive correlation between morpho-biochemical leaf traits and main grain yield components shows that concur significative to improve the final grain yield manifestation. Siloryia et al. (2014) reported that between leaf area index and weight of grains per panicle is a positive relationship, highlighted also in our research by correlation coefficient $(\mathrm{r}=0.88)$ between these two traits. Hisir et al. (2012) reported grain yield was positively and significantly correlated with leaf area index in a study regarding the grain yield performance and physiological traits of 17 oat genotypes in Mediterranean typical climate.

\section{Conclusion}

These study shows the importance of morphobiochemical traits, such as Leaf Area Index and Chlorophyll Concentration, and their significant contribution on grain yield expression. Results of correlation showed that grain yield or main yield components are correlated significant and positive with flag leaf area and chlorophyll concentration.

\section{References}

1. Aldesuquy H, Baka Z, Mickky B (2014). Kinetin and spermine mediated induction of salt tolerance in wheat plants: Leaf area, photosynthesis and chloroplast ultrastructure of flag leaf at ear emergence, Egyptian Journal of Basic and Applied Sciences, 1: 77-87.

2. Berwal MK, Goyal P, Chugh LK, Kumar R (2017). Impact of Flag Leaf Removal on Grain Development and Nutrients Deposition in Pearl Millet Developing Grains. Vegetos 31:1.

3. Sadiq Butt $M$, Tahir-Nadeem M, Kashif Iqbal Khan $M$, Shabir R, Sadiq Butt M (2008). Oat: unique among the cereals, European Journal of Nutrition, 47: 68 - 79.

4. Siloriya P N, Rathi GS, Meena VD (2014). Relative performance of oat (Avena sativa L.) varieties for their growth and seed yield, African Journal of Agricultural Research, 9 (3): 425-431.

5. HisirY, Kara R, Dokuyucu T (2012). Evaluation of oat (Avena sativa L.) genotypes for grain yield and physiological traits, Žemdirbystè=Agriculture, 99(1): 55-60. 